\title{
DFT-Quantum Spectroscopic Studies and Anti-Cancer Effect of Ibuprofen Drug and Some Analogues
}

\author{
Anwar El-Shahawy', Hana Gashlan², Safaa Qusti², Ghada Ezzat ${ }^{3}$, \\ Hossam Emara ${ }^{1}$ \\ ${ }^{1}$ Chemistry Department, Faculty of Science, Assiut University, Assiut, Egypt \\ ${ }^{2}$ Biochemistry Department, Faculty of Science, King Abdulaziz University, Jeddah, Saudi Arabia \\ ${ }^{3}$ Biochemistry Department, Faculty of Medicine, Assiut University, Assiut, Egypt \\ Email: anwarshahawy@gmail.com
}

Received 12 March 2016; accepted 25 April 2016; published 28 April 2016

Copyright (C) 2016 by authors and Scientific Research Publishing Inc.

This work is licensed under the Creative Commons Attribution International License (CC BY).

http://creativecommons.org/licenses/by/4.0/

(c) (i) Open Access

\begin{abstract}
From our DFT calculations of Ibuprofen drug (IBF) and other related molecules such as 2-Phenylpropanoic acid (2-PPA) and 3-Phenylpropanoic acid (3-PPA), it has been found that the ionization potential energies of their anions are decreased strongly, with respect to their values in the molecular forms, rendering them as spontaneous electron donor which can compensate the electron deficiency for the positive cancer cells. Time dependent calculations show good coincidence with the experimental absorption spectra. Some complexes of IBF are prepared with $\mathrm{Cu}^{++}$and $\mathrm{Zn}^{++}$ions. The ratio between the $\mathrm{M}^{++}$and the ligand (IBF) is $1: 2$ which has been verified by atomic absorption spectra and elemental analyses. Their spectral studies have been performed in different solvents of different polarities. The metabolite products of IBF have been studied from DFT calculations point of view and it has been concluded that the consistency of the ionization constants and the electron affinities of them with those of the nucleic acid bases prevents the electron transfer between them therefore they are safe for the human body from cancer diseases.
\end{abstract}

Keywords

DFT/6-31G**, IBF, 2PPA, 3PPA, Anions, $\mathrm{Cu}^{++}, \mathrm{Zn}^{++}$, Cancer, UVspectra

\section{Introduction}

Cancer is a leading cause of death in both more and less economically developed countries due to tobacco use,

How to cite this paper: El-Shahawy, A., Gashlan, H., Qusti, S., Ezzat, G. and Emara, H. (2016) DFT-Quantum Spectroscopic Studies and Anti-Cancer Effect of Ibuprofen Drug and Some Analogues. Computational Chemistry, 4, 33-50. 
obesity, physical inactivity, and infections [1]. Ibuprofen drug is a member of the class of drugs termed as non-steroidal anti-inflammatory drugs (NSAIDS), with anti-inflammatory, analgesic, and antipyretic activity. Recently, the regular use of ibuprofen prevents from some certain cancers including prostate, colon, breast, lung, and gastric cancers due to the inhibition of cyclooxygenase-2(COX-2) [2] [3]. Reduced Risk of Human Lung Cancer by Selective Cyclooxygenase 2 (Cox-2) Blockade was studied by Harris et al. [4]. The 2-arylpropanoic acids (2-APAs) are an important group of non-steroidal anti-inflammatory drugs, the majority of which are remarked as racemic mixtures because they have asymmetric carbon atom. These drugs exhibit stereoselectivity in both their pharmacological activity, i.e. inhibition of cyclo-oxygenase [5]. The lattice energy of ibuprofen crystals which is calculated using DFT method agrees with the experimental values especially with polymorphism of the crystals [6]. The conformational stability of ibuprofen, due to a para-substituted group in the molecule, is carried out using DFT calculations coupled with optical vibrational spectroscopy. The calculated frequencies and intensities prove the presence of the lowest energy conformers in the solid state and intermolecular hydrogen bonds between the carboxylic groups of adjacent molecules leading to formation of dimmers [7]. In the frame of theoretical studies of ibuprofen, the action of ibuprofen is due to electrophilic attack on the oxygen atoms of carboxyl group [8]. The superior DFT methods in predicting the structures of ibuprofen are mPW1PW91/6-311++G (d, p) and mPW1PW91/6-311++G (2d, 2p) while B3PW91/6-311++G (2d, 2p) is the best method to predict all vibrational frequencies of the molecule [9]. In this work, it has been suggested that the anti-cancer effect of the ibuprofen and its analogues is due to their anionic and molecular forms of the drug side by side in the human body specifically for the positive cancer cells.

\section{Experimental Work}

\subsection{Apparatuses}

All melting points of the studied compounds have been determined on a Gallen-Kamp melting point apparatus.

The elemental analyses (C, H, N) were determined using Elementer Analyses system (GmbH, Donaustr-7, D-63452) Hanau, (Germany).

The electronic absorption spectra of the studied compounds had been scanned by uv-2011 PC, uv-vis scanning spectrophotometer (Shimadzu) using $1 \mathrm{~cm}$ matched silica cells.

The atomic absorption spectra of the complexes were studied by using an atomic absorption spectrophotometer (Buck Scientific Model 210 GVP).

\subsection{Materials and Methods}

All materials supplied to our experimental work were bought from the different companies without further purification. Ibuprofen (IBF) was bought from Sigma Aldrich and 2-Phenylpropanoic acid (2-PPA) was bought from Alfa Aesar as well as 3-Phenylpropanoic acid (3-PPA).

Ibuprofen (2.06 g, 0.01 moles) was allowed to be dissolved in a solution of potassium bicarbonate (1.10 g, 0.011 mole) in $80 \mathrm{ml}$ of water. During stirring the solution, $\mathrm{CuSO}_{4} \cdot 5 \mathrm{H}_{2} \mathrm{O}$ was added slowly (1.25 g, 0.005 mole) in $10 \mathrm{ml}$ of water. The mixture was allowed to be stirred for 30 minutes. The aquamarine precipitated and was collected, washed with water followed by ethanol, and then recrystallized from ether. The product was air-dried, [10].

2.0 Mmoles ( $0.412 \mathrm{~g})$ of ibuprofen react with 2.0 mmoles $(0.112 \mathrm{~g})$ of $\mathrm{KOH}$ dissolved in $20 \mathrm{~mL}$ of distilled water, to give the potassium salt of the ligand. Then 1.0 mmole $(0.2195 \mathrm{~g})$ of $\mathrm{Zn}\left(\mathrm{CH}_{3} \mathrm{COO}\right)_{2} \cdot 2 \mathrm{H}_{2} \mathrm{O}$ (aqueous solution) was added during stirring. The white needle precipitated and collected by filtration, washed several times with distilled water and acetone, then dried in vacuum, [11]. The melting points of the studied compounds have been presented in Table 1.

From elemental analysis, Table 2, and atomic absorption spectra, Table 3 it has been shown that the ratio between metal ions, $\mathrm{Cu}^{++}$or $\mathrm{Zn}^{++}$with IBF ligand is 1:2 in their complexes.

\section{Method of Calculations}

\subsection{Spectral Constants}

The absolute intensity of band absorption can be calculated and it has been shown that Einstein transition probabilities coefficients, [12] [13] of the emission, A, and the absorption, B, between two electronic states i.e. the 
Table 1. Melting points of ibuprofen, 3-PPA, Copper(II) and Zinc(II) complexes with ibuprofen.

\begin{tabular}{cc}
\hline Compound & Melting point range ${ }^{\circ} \mathrm{C}$ \\
IBF & $74-76$ \\
$3-\mathrm{PPA}$ & $44-48$ \\
$\mathrm{Cu}(\mathrm{IBF})_{2}$ & $250-252$ \\
$\mathrm{Zn}(\mathrm{IBF})_{2} \cdot 2 \mathrm{H}_{2} \mathrm{O}$ & $78-82$ \\
\hline
\end{tabular}

Table 2. Elemental analysis of Copper(II) and Zinc(II) complexes with Ibuprofen.

\begin{tabular}{ccccc}
\hline \multirow{2}{*}{ Compound } & \multicolumn{2}{c}{ \% Theoretical } & \multicolumn{2}{c}{ \% Experimental } \\
\cline { 2 - 5 } & $\mathrm{C}$ & $\mathrm{H}$ & $\mathrm{C}$ & $\mathrm{H}$ \\
\hline $\mathrm{Cu}(\mathrm{IBF})_{2}$ & 65.87 & 7.23 & 63.74 & 6.55 \\
$\mathrm{Zn}(\mathrm{IBF})_{2} \cdot 2 \mathrm{H}_{2} \mathrm{O}$ & 60.10 & 7.48 & 60.40 & 7.44 \\
\hline
\end{tabular}

Table 3. Atomic absorption of Copper(II) and zinc(II) complexes with Ibuprofen.

\begin{tabular}{ccc}
\hline \multirow{2}{*}{ Compound } & \% Theoretical & \% Experimental \\
\cline { 2 - 3 } & $\mathrm{M}^{+2}$ & $\mathrm{M}^{+2}$ \\
\hline $\mathrm{Cu}(\mathrm{IBF})_{2}$ & 13.40 & 12.95 \\
$\mathrm{Zn}(\mathrm{IBF})_{2} \cdot 2 \mathrm{H}_{2} \mathrm{O}$ & 12.77 & 12.1 \\
\hline
\end{tabular}

ground state I, and the excited state $\mathrm{f}$, are given as follows:

$$
\begin{gathered}
A_{i f}=\frac{64 \pi^{4} \tilde{v}^{3} e^{2}}{3 h} G_{f} D_{i f} \\
B_{i f}=\frac{8 \pi^{3} e^{2}}{3 h^{2} C} G_{f} D_{i f}
\end{gathered}
$$

where:

$e=$ The charge of the electron

$h=$ Planck's constant

$C=$ The velocity of light, $3 \times 10^{10} \mathrm{~cm} \cdot \mathrm{sec}^{-1}$

$\tilde{v}=$ The wave number in $\mathrm{cm}^{-1}$

$G_{f}=$ Degeneracy of the state

$D_{\text {if }}=$ Dipole strength

Substituting the numerical values and assuming that degeneracy of the state is singlet, then:

$$
\begin{aligned}
& A_{i f}=7.24 \times 10^{10} \tilde{v}^{3} D_{i f} \\
& B_{i f}=14.50 \times 10^{24} D_{i f}
\end{aligned}
$$

Mulliken related the quantity $B_{i f}$ to the Oscillator strength, $F$, which is the measure of the intensity.

$$
f=\frac{8 \pi^{2} m c}{3 h} G f \tilde{v} D_{i f}=1.085 \times 10^{11} G_{f} \tilde{v} D_{i f}
$$

Also the Oscillator strength can be related to the absolute intensity as follows: 


$$
f=0.102\left(\frac{m c^{2}}{N \pi e^{2}}\right) \int \varepsilon \mathrm{d} \tilde{v}=4.315 \times 10^{-9} \int \varepsilon \mathrm{d} \tilde{v}
$$

where: $m=$ The mass of electron

$N=$ The Avogadro's number

$\varepsilon=$ Molar extinction coefficient

if a molecule or an atom is in an excited state then, in the absence of an external electromagnetic field, on the average, after a time of $\tau=\frac{1}{A_{i f}}$ where $A_{i f}$ is the Einstein spontaneous transition probability coefficient from the excited state to the ground state, it will emit a photon. $\tau$ is called the mean lifetime of the excited state. Generally $D_{i f}$ can be calculated numerically as follows:

$$
D_{i f}=4.23671 \times 10^{-20} \times \frac{c \hbar}{v} \varepsilon_{\max } .
$$

where $\hbar$ is the half width of the absorption band in $\mathrm{cm}^{-1}$. hence, the oscillator strength can be calculated directly as follows:

$$
f=4.6 \times 10^{-9} \varepsilon_{\max } \times \hbar
$$

\subsection{DFT Calculations}

Computational studies on the isolated molecules in the gas phase were performed by the aid of GAUSSIAN 03 package. Minimum energy structures have been achieved using semi-empirical AM1 method. DFT/6-31**G calculations were performed on the minimum energy structures using the closed shell Hartree-Fock, Becke's three parameters density functional theory, DFT, [12] [13] in combination with the Lee, Yang and Parr correlation functional B3LYP. The differentiation between the conformers' $\mathrm{R}$ and $\mathrm{S}$ of the ibuprofen drug was based on the total energy difference which has been calculated via SCF using RHF for these types of molecules and UHF for the molecular anions.

With respect to DFT calculations, it has been carried out as B3LYP/6-31**G and the energy of the DFT theory can be represented as a function of the electron density as follows:

$$
E|\rho|=\frac{-\hbar^{2}}{2 m_{e}} \sum_{i=1}^{n} \int \psi_{i}^{*}\left(r_{1}\right) \nabla^{2} \psi_{i}\left(r_{1}\right) \mathrm{d} r_{1}-\sum_{i=1}^{n} \int \frac{z_{r} e^{2}}{4 \pi \varepsilon_{o} r_{11}} \rho\left(r_{1}\right) \mathrm{d} r_{1}+\frac{1}{2} \int \frac{\rho\left(r_{1}\right) \rho\left(r_{2}\right) e^{2}}{4 \pi \varepsilon_{0} r_{12}} \mathrm{~d} r_{1} \mathrm{~d} r_{2}+E_{x c}|\rho| \quad \text { where } \hbar=\frac{h}{2 \pi}
$$

where $\rho$ is the electron density

$$
\rho=\sum_{i=1}^{\text {HOMO }}\left|\psi_{i(r)}\right|^{2}=\sum_{i=1}^{\text {HOMO }} C_{i(r)}^{2}
$$

where $C_{i}$ is the eigenvectors for each eigenfunction $\Psi_{i}$ and

$$
\hat{H}_{i}=\frac{-\hbar^{2}}{2 m_{e}} \nabla_{i}^{2}-\sum_{i}^{n} \frac{z_{1} e^{2}}{4 \pi \varepsilon_{0} r_{12}}+\int \frac{\rho\left(r_{2}\right) e^{2}}{4 \pi \varepsilon_{0} r_{12}}+V_{x c}\left(r_{1}\right)
$$

where $\hat{H}_{i}$ is the total energy Hamiltonian operator. $\varepsilon$ is the permittivity of the vacuum.

\section{Results and Discussion}

\subsection{Spectroscopic Studies}

Ibuprofen, 2 (4-isobutylphenylpropanoic acid (IBF), is a non-steroidal anti-inflammatory drug (NSAID) which can be used for relieving pain, antipyretic and anti-inflammatory. About $60 \%$ of patients improve with any given NSAID and it is advised that if one does not work that another can be used. Ibuprofen may be considered as weak anti-inflammatory than other NSAIDs. IBF molecule has two conformers $R$ and $S$ as shown in the following Figure 1. Ibuprofen has a particularly interesting property, and it can exist as a pair of optical isomers that 


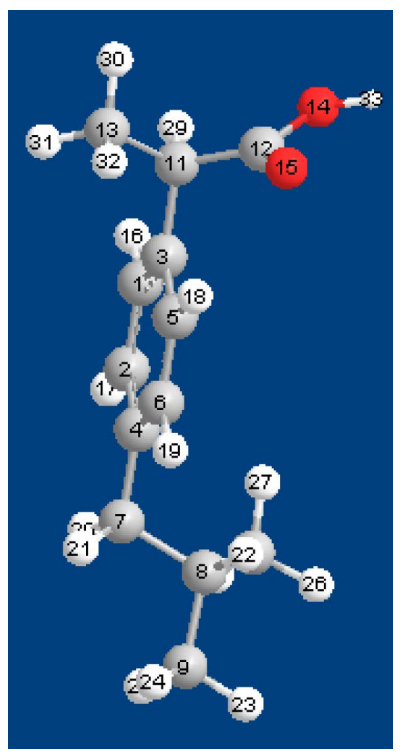

R-FORM

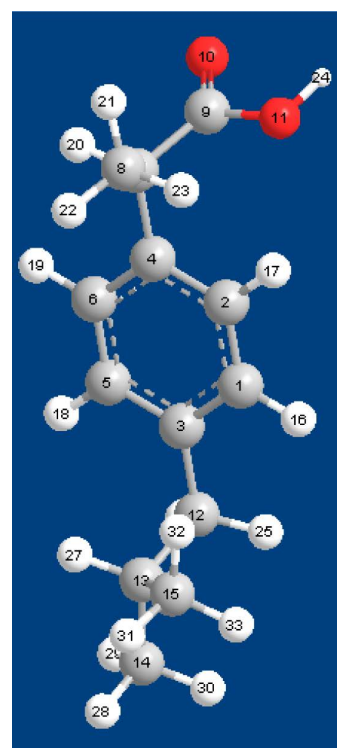

S-FORM

Figure 1. Minimum energy structures of Ibuprofen isomers.

are mirror images of each other. These mirror images are non-super-imposable, which are mirror images but not identical. This mirror image property occurs in molecules that have asymmetric carbon atom. The two optical isomers of ibuprofen are identified by the prefixes $R^{-}$(Levo Rotatory) and $S^{+}$(Dextro Rotatory). DFT calculations have been performed according to El-Shahawy, [12] [13] using the basis set 6-31** G.

From the previous Table 4, it has been shown that the energy difference between the $S$ and $R$ forms is very small being equal to $0.02839 \mathrm{eV}$ which is too small to make a significant difference in the temperature effect, Figure 2, on the spectrum in ethanol solvent, [14]. Therefore IBF molecules exist in the two forms in a racemic mixture. From the energy difference between the two forms it has been calculated that the ratio between them equal 0.35 of the S-conformer of higher energy this means that the R-form is the predominant form in the IBF drug i.e. $65 \%$ at $37^{\circ} \mathrm{C}$. The two forms have nearly the same constants of ionization potential, Ip, and electron affinity Ea, except the dipole moment of the S-form is higher than that of R-form.

From the previous Table 5, it can be concluded that the IBF molecule, even $S$ or $R$, form has lower energy than those of phenyl derivatives of propanioc acid which have higher ionization potentials than those of IBF forms. The electron affinities of 2-PPA and $\mathrm{Zn}(\mathrm{IBF})_{2}$ are higher than those of the studied compounds. The S-IBF and 2-PPA have the higher dipole moments among all the other compounds.

Regarding the HOMO of IBF molecule even in the R and S-forms, it is $\psi_{m}$ in each singlet configuration eigenfunctions of the excited states. From the previous Table 6, it has been noticed that the first excited state of R-form includes the configurations of transitions $\psi_{m-2} \rightarrow \psi_{m+1}, \psi_{m} \rightarrow \psi_{m+1}, \psi_{m} \rightarrow \psi_{m+3}$ and $\psi_{m} \rightarrow \psi_{m+4}$. The configuration eigenfunction of highest contribution in the first excited state is that includes the transition $\psi_{m} \rightarrow \Psi_{m+1}$ of eigenvector 0.60334. From the previous Table 7, it can be noticed that the first excited state of S-form is constituted from the configuration eigenfunctions of transitions $\psi_{m-2} \rightarrow \psi_{m+1}, \psi_{m-2} \rightarrow \psi_{m+5}, \psi_{m} \rightarrow \psi_{m+1}$ and $\psi_{m} \rightarrow$ $\psi_{m+2}$ and $\psi_{m} \rightarrow \psi_{m+5}$. The configuration which has high contribution in the transition to the first excited state contains the transition $\psi_{m} \rightarrow \psi_{m+1}$ of eigenvector 0.55621 in case of S-form. In the second singlet excited state of the R-form, the contributions of configuration eigenfunctions containing the transitions $\psi_{m-1} \rightarrow \psi_{m+1}$ and $\psi_{m} \rightarrow$ $\psi_{m+2}$ are the highest as well as in case of the S-form, Table 6, Table 7. For the R-form, the third excited state includes the highest configuration eigenfunction of the transition $\psi_{m-2} \rightarrow \psi_{m+1}$ as well as in case of the S-form. It is shown from the previous Table 6, Table 7, that the first transitions from the ground state to the firs excited state for the two conformers lies at the same wavelength $445 \mathrm{~nm}$ which has not any change in the uv-spectrum of IBF drug by the temperature effect [14].

From the previous Figure 3 and Table 8, of IBF spectra, it has been shown that there is some broadness in the top of the absorption bands in different solvents and of course the temperature effect doesn't show any change in the relative intensity, Figure 2, due to the very small energy difference between the two conformers $R$ and $S$ 


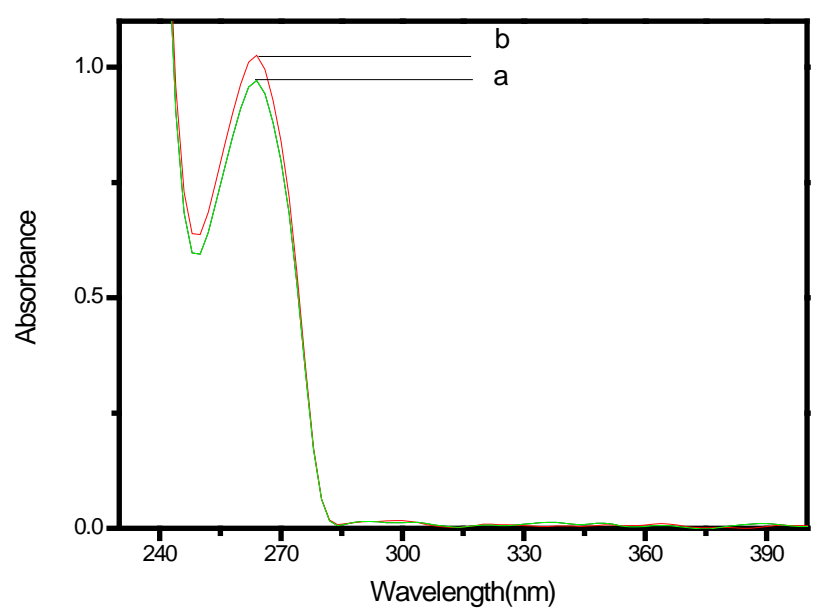

Figure 2. Electronic spectra of Ibuprofen $\left(403 \mathrm{mmol} \cdot \mathrm{L}^{-1}\right)$ in ethanol at different temperature: $\mathrm{a}=25^{\circ} \mathrm{C} ; \mathrm{b}=40^{\circ} \mathrm{C}$.

Table 4. DFT-Data of the optical isomers of IBF in the ground state.

\begin{tabular}{ccccrr}
\hline Form of IBF & TE au & $\Delta \mathrm{E}$ & IP eV & Ea & Dip. Mom. D \\
\hline S-IBF & -656.5408 & $0.0010397 \mathrm{au}$ & 6.6837 & 0.8879 & 2.2182 \\
R-IBF & -656.5419 & $0.0282917 \mathrm{eV}$ & 6.6766 & 0.9048 & 1.4383 \\
\hline
\end{tabular}

Table 5. Comparative DFT parameters of Ibuprofen and some analogues.

\begin{tabular}{ccccc}
\hline Compound & TE au & Ip eV & Ea eV & 0.8879 \\
S-IBF & -656.5408 & 6.6837 & 0.9048 & 1.2182 \\
R-IBF & -656.5419 & 6.6766 & 0.9633 & 0.8768 \\
2-PPA & -499.3220 & 7.0146 & 1.9947 \\
3-PPA & -499.3209 & 6.8812 & 1.38397 & 1.6931 \\
Cu(IBF)2 & -2952.01917046 & 6.53509 & 2.479230 \\
Zn(IBF)2 & -3090.86733452 & 6.494817 & 1.4591 \\
\hline
\end{tabular}

N.B. 2-PA is 2-phenyl propanioc acid and 3-PA is 3-phenyl propanioc acid. Ip is the ionization potential, Ea is the electron affinity and Dip. Mom. Is dipole moment.

Table 6. Excitation energies and oscillator strengths of R-form of IBF in the gaseous state.

\begin{tabular}{|c|c|c|c|c|c|c|}
\hline $\begin{array}{l}\text { Excited State } \\
\text { Singlet-A }\end{array}$ & Eigenvectors & Transition & $\Delta \mathrm{E} \mathrm{eV}$ & $\lambda_{\text {calc. }} \mathrm{nm}$ & $\mathrm{f}$ & $\lambda_{\text {exp. }} \mathrm{nm}$ \\
\hline \multicolumn{7}{|c|}{ Excited State 1} \\
\hline $\begin{array}{l}54 \rightarrow 57 \\
56 \rightarrow 57 \\
56 \rightarrow 59 \\
56 \rightarrow 60\end{array}$ & $\begin{array}{c}-0.22953 \\
0.60334 \\
0.11187 \\
0.10821\end{array}$ & $\begin{array}{c}\psi_{m-2} \rightarrow \psi_{m+1} \\
\psi_{m} \rightarrow \psi_{m+1} \\
\psi_{m} \rightarrow \psi_{m+3} \\
\psi_{m} \rightarrow \psi_{m+4}\end{array}$ & 5.0675 & $245 \mathrm{~nm}$ & 0.0843 & $263 \mathrm{~nm}$ \\
\hline \multicolumn{7}{|c|}{ Excited State 2} \\
\hline $\begin{array}{l}54 \rightarrow 57 \\
55 \rightarrow 57 \\
55 \rightarrow 60 \\
55 \rightarrow 61 \\
56 \rightarrow 58 \\
56 \rightarrow 59\end{array}$ & $\begin{array}{c}-0.14064 \\
-0.45550 \\
0.10498 \\
-0.10824 \\
0.47239 \\
0.10670\end{array}$ & $\begin{array}{c}\psi_{m-2} \rightarrow \psi_{m+1} \\
\psi_{m-1} \rightarrow \psi_{m+1} \\
\psi_{m-1} \rightarrow \psi_{m+4} \\
\psi_{m-1} \rightarrow \psi_{m+5} \\
\psi_{m} \rightarrow \psi_{m+2} \\
\psi_{m} \rightarrow \psi_{m+3}\end{array}$ & 5.1952 & $238.65 \mathrm{~nm}$ & 0.0016 & $231 \mathrm{~nm}$ \\
\hline \multicolumn{7}{|c|}{ Excited State 3} \\
\hline $\begin{array}{l}54 \rightarrow 57 \\
54 \rightarrow 59 \\
54 \rightarrow 60 \\
56 \rightarrow 57 \\
56 \rightarrow 58\end{array}$ & $\begin{array}{l}0.56731 \\
0.15448 \\
0.13998 \\
0.26587 \\
0.12041\end{array}$ & $\begin{array}{c}\psi_{m-2} \rightarrow \psi_{m+1} \\
\psi_{m-2} \rightarrow \psi_{m+3} \\
\psi_{m-2} \rightarrow \psi_{m+4} \\
\psi_{m} \rightarrow \psi_{m+1} \\
\psi_{m} \rightarrow \psi_{m+2}\end{array}$ & 5.3933 & 229.89 & 0.0177 & \\
\hline
\end{tabular}




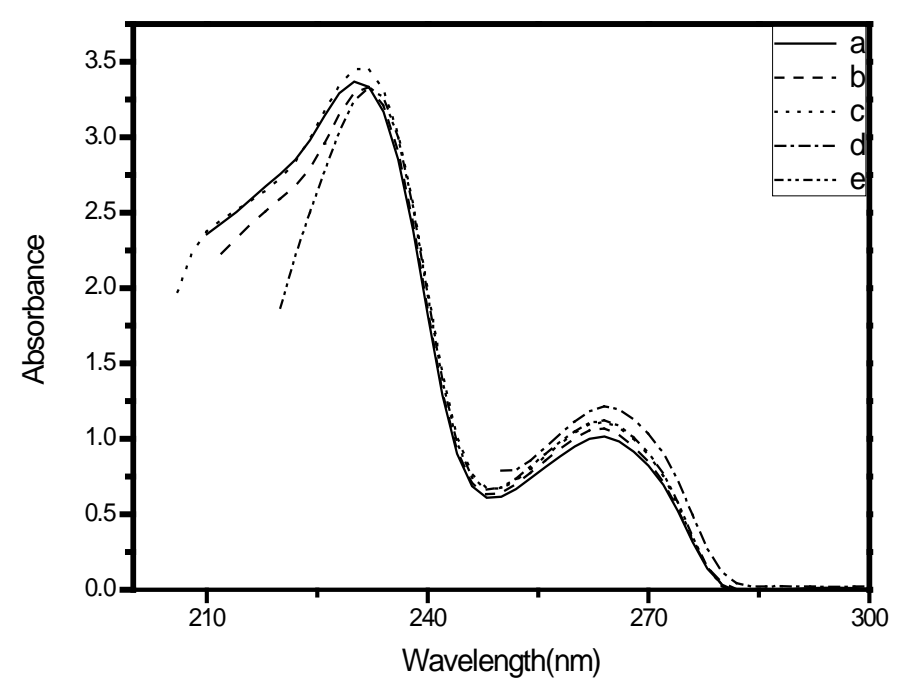

Figure 3. Electronic spectra of Ibuprofen $\left(403 \mathrm{mmol} \cdot \mathrm{L}^{-1}\right.$ in) (a) EtOH

(b) $\mathrm{MeOH}$, (c) Isopropanol, (d) $\mathrm{CHCl}_{3}$, and (e) Cyclohexane.

Table 7. Excitation energies and oscillator strengths of S-form of IBF in the gas phase.

\begin{tabular}{|c|c|c|c|c|c|c|}
\hline $\begin{array}{l}\text { Excited State } \\
\text { Singlet-A }\end{array}$ & Eigenvectors & Transition & $\Delta \mathrm{E} \mathrm{eV}$ & $\lambda_{\text {calc. }} \mathrm{nm}$ & $\mathrm{F}$ & $\lambda_{\text {exp. }} \mathrm{nm}$ \\
\hline \multicolumn{7}{|c|}{ Excited State 1} \\
\hline $54 \rightarrow 57$ & 0.29826 & $\psi_{m-2} \rightarrow \psi_{m+1}$ & \multirow{5}{*}{4.9819} & \multirow{5}{*}{$245 \mathrm{~nm}$} & \multirow{5}{*}{0.0658} & \multirow{5}{*}{$263 \mathrm{~nm}$} \\
\hline $54 \rightarrow 61$ & -0.11518 & $\psi_{m-2} \rightarrow \psi_{m+5}$ & & & & \\
\hline $56 \rightarrow 57$ & 0.55621 & $\psi_{m} \rightarrow \psi_{m+1}$ & & & & \\
\hline $56 \rightarrow 58$ & -0.17879 & $\psi_{m} \rightarrow \psi_{m+2}$ & & & & \\
\hline $56 \rightarrow 61$ & -0.11978 & $\psi_{m} \rightarrow \psi_{m+5}$ & & & & \\
\hline \multicolumn{7}{|c|}{ Excited State 2} \\
\hline $54 \rightarrow 57$ & 0.12731 & $\psi_{m-2} \rightarrow \psi_{m+1}$ & \multirow{7}{*}{5.2043} & \multirow{7}{*}{238.24} & \multirow{7}{*}{0.0104} & \multirow{7}{*}{$231 \mathrm{~nm}$} \\
\hline $55 \rightarrow 57$ & 0.42453 & $\psi_{m-1} \rightarrow \psi_{m+1}$ & & & & \\
\hline $55 \rightarrow 58$ & 0.10408 & $\psi_{m-1} \rightarrow \psi_{m+2}$ & & & & \\
\hline $55 \rightarrow 61$ & 0.15894 & $\psi_{m-1} \rightarrow \psi_{m+5}$ & & & & \\
\hline $56 \rightarrow 58$ & 0.41711 & $\psi_{m} \rightarrow \psi_{m+5}$ & & & & \\
\hline $56 \rightarrow 59$ & -0.25061 & $\psi_{m} \rightarrow \psi_{m+3}$ & & & & \\
\hline $56 \rightarrow 61$ & -0.14454 & $\psi_{m} \rightarrow \psi_{m+5}$ & & & & \\
\hline \multicolumn{7}{|c|}{ Excited State 3} \\
\hline $54 \rightarrow 57$ & 0.52994 & $\psi_{m-2} \rightarrow \psi_{m+1}$ & \multirow{4}{*}{5.4852} & \multirow{4}{*}{226.03} & \multirow{4}{*}{0.0497} & \\
\hline $54 \rightarrow 58$ & -0.12594 & $\psi_{m-2} \rightarrow \psi_{m+2}$ & & & & \\
\hline $54 \rightarrow 61$ & -0.17235 & $\psi_{m-2} \rightarrow \psi_{m+5}$ & & & & \\
\hline $56 \rightarrow 57$ & -0.34971 & $\psi_{m} \rightarrow \psi_{m+1}$ & & & & \\
\hline
\end{tabular}

Table 8. Spectral parameters, Einstein probabilities $\left(A_{i f}\right.$ and $\left.B_{i f}\right)$, dipole strength $\left(D_{i f}\right)$, oscillator strength $\left(F_{i f}\right)$, lifetime $(\tau)$ and extinction coefficient $\left(\varepsilon_{\max }\right)$ of the electronic transition bands of Ibuprofen in different solvents.

\begin{tabular}{|c|c|c|c|c|c|c|c|}
\hline Solvent & $\max \lambda$ & $A_{i f} 10^{-7} \mathrm{~S}^{-1}$ & $B_{i f} 10^{-7} \mathrm{~s} \cdot \mathrm{g}^{-1}$ & $D_{\text {if }} 10^{18}$ & $f_{\text {if }} 10^{2}$ & $\varepsilon_{\max }$ & $\tau \mathrm{ns}$ \\
\hline \multirow{2}{*}{ Ethanol } & 230.05 & 2.45 & 3.00 & 4.14 & 1.95 & 830.78 & 40.82 \\
\hline & 263.51 & 0.455 & 1.67 & 1.15 & 0.476 & 254.41 & 219.78 \\
\hline \multirow{2}{*}{ Methanol } & 230.89 & 2.13 & 5.28 & 3.64 & 1.71 & 827.39 & 46.95 \\
\hline & 263.68 & 0.457 & 1.68 & 1.16 & 0.478 & 264.90 & 218.82 \\
\hline \multirow{2}{*}{ Isopropanol } & 230.76 & 2.29 & 5.66 & 3.90 & 1.84 & 855.45 & 43.67 \\
\hline & 263.68 & 0.479 & 1.76 & 1.22 & 0.501 & 273.23 & 208.77 \\
\hline \multirow{2}{*}{ Cyclohexane } & 231.60 & 2.00 & 4.99 & 3.44 & 1.61 & 822.45 & 50.00 \\
\hline & 263.42 & 0.490 & 1.80 & 1.24 & 0.512 & 277.23 & 204.08 \\
\hline Chloroform & 264.20 & 0.523 & 1.94 & 1.34 & 0.549 & 299.51 & 191.21 \\
\hline
\end{tabular}


[14]. However, the maximum absorption band positions exist at the same values 231 and $263 \mathrm{~nm}$ even by using different solvents with different polarities indicating to non-polarized ground and excited states for this molecule. The Einstein transition probabilities $\left(A_{i f}\right.$ and $\left.B_{i f}\right)$, oscillator strength $f_{i \text {, }}$, dipole strength $D_{\text {if }}$ and the life time of excitation $\tau$ between the initial (i) and the final (f) electronic states have been calculated according to El-Shahawy [12] [13]. The spontaneous transition probability $A_{i f}$, of IBF spectra in different solvents of different polarity has values which are higher at $\lambda_{\max }=231 \mathrm{~nm}$ than those at $\lambda_{\max }=263 \mathrm{~nm}$ as well as the same situation in the values of the induced transition probability, $B_{i f}$, of IBF spectra. The dipole strength $D_{i f}$ values are higher at $\lambda_{\max }=231$ than those at $\lambda_{\max }=263 \mathrm{~nm}$. The absorption bands at $\lambda_{\max }=231 \mathrm{~nm}$ have higher oscillator strengths $f_{\text {if }}$ than those at $\lambda_{\max }=263 \mathrm{~nm}$ and this appears in Figure 3, that the absorption bands at $\lambda_{\max }=231 \mathrm{~nm}$ have higher intensities more than those at $\lambda=263 \mathrm{~nm}$ in different solvents. The life time of the electronic excited states $\tau$, of this molecule has average value $\sim 200 \mathrm{~ns}$ for the transitions at $\lambda_{\max }=263 \mathrm{~nm}$ but it has lower average value $\sim 45 \mathrm{~ns}$ for the transitions at $\lambda_{\max }=231 \mathrm{~nm}$.

The ultraviolet spectra of 2-Phenylpropanoic acid Figure 4, show bands at $\lambda=257 \mathrm{~nm}$ and at $\lambda_{\max }=228 \mathrm{~nm}$ which have the induced transition probability $\left(B_{f}\right)$ in different solvents being higher than those of the spontaneous transition probability $\left(A_{i f}\right)$ as in the same case of IBF spectra. The molar absoptivities of the two absorption bands at $\lambda_{\max }=231$ and $\lambda_{\max }=263$ in the IBF spectra are higher, Table 8, than those of absorption bands $\lambda_{\max }=$ 228 and $\lambda_{\max }=257 \mathrm{~nm}$ in the spectra of 2-Phenylpropanoic acid, Table 9. The oscillator strengths $f_{i f}$, in 2-Phenylpropanoic acid spectra in different solvents are lower than those of IBF spectral bands. The dipole strengths $D_{\text {if }}$ of 2-Phenylpropanoic acid absorption bands in different solvents are lower than those of IBF but the life times of the excited states of the absorption bands in the spectra of 2-Phenylpropanoic acid are higher than those of IBF spectral bands. From the previous Table 10, the transition energy from the ground state to the first excited state lies at $244 \mathrm{~nm}$ which is corresponding to an experimental value at $257 \mathrm{~nm}$, Table 9. This first excited state of minimum energy structure of 2-PPA, Figure 5, is composed from configuration eigenfunctions of the electronic transitions $\psi_{m-2} \rightarrow \psi_{m+1}, \psi_{m-2} \rightarrow \psi_{m+4}, \psi_{m} \rightarrow \psi_{m+1}, \psi_{m} \rightarrow \psi_{m+2}$ and $\psi_{m} \rightarrow \psi_{m+4}$. The main configuration eigenfunction in the first excited state having the transition $\psi_{m}-\psi_{m+1}$ of eigenvector 0.49968 . The calculated transition energy to the second excite state at $\lambda=233 \mathrm{~nm}$ has good coincidence with the experimental position at $\lambda=228 \mathrm{~nm}$ and the main configuration eigenfunction of high contribution in the second excited state includes the transition $\psi_{m-1-} \rightarrow \psi_{m+1}$ of eigenvector 0.49872. The eigenfunction of high contribution in the third excited state includes the transition $\psi_{m-2} \rightarrow \psi_{m+1}$ of eigenvector 0.46682 .

The first calculated electronic transition from the ground state to the first singlet state lies at $236 \mathrm{~nm}$ which is not far from the experimental maximum wavelength at $259 \mathrm{~nm}$, Table 11. From comparison point of view between the spectral parameters between 2-PPA and 3-PPA it can be noticed that the Einstein transition probabilities $\left(A_{i f}\right.$ and $B_{i f}$ ), dipole sstrength $D_{\text {if }}$ and oscillator strength $F_{\text {if }}$ of 2-PPA are higher than those of 3-PPA spectral parameters but the life time of excitation of 3-PPA is higher than that of 2-PPA spectral parameters, Table 9,

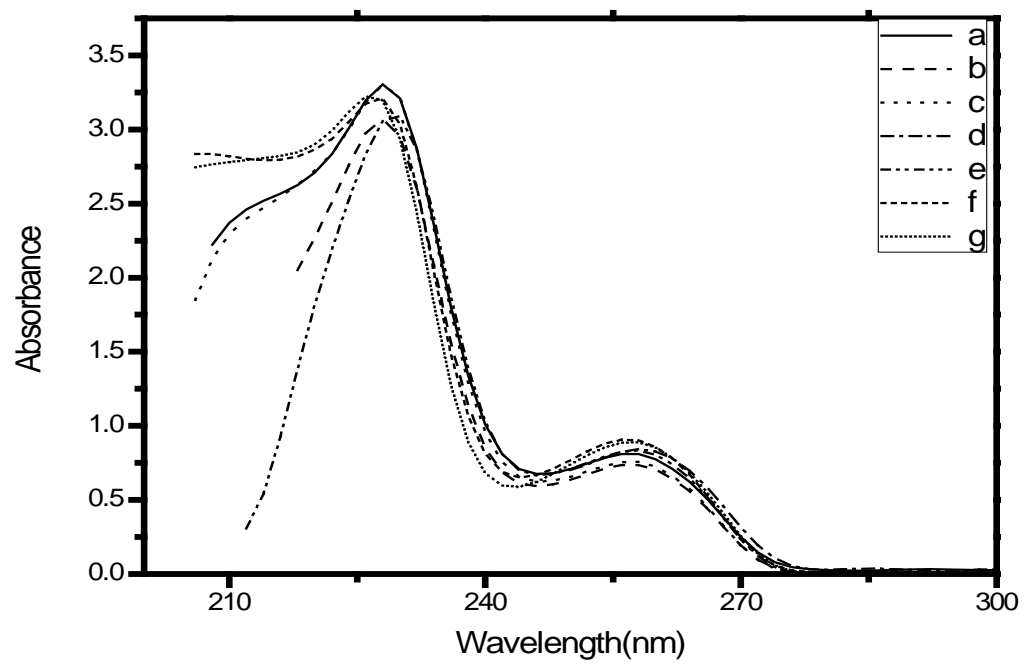

Figure 4. Electronic spectrum of 2-Phenylpropanoic acid (452 $\mathrm{mmol} \cdot \mathrm{L}^{-1}$ ) in (a) $\mathrm{EtOH}$, (b) $\mathrm{MeOH}$, (c) Isopropanol, (d) $\mathrm{CHCl}_{3}$ and (e) Cyclohexane. 


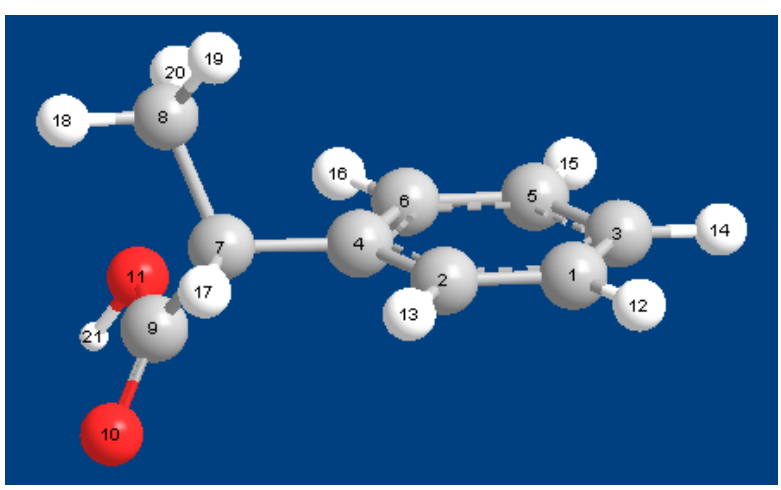

Figure 5. Minimum energy structure of 2-Phenylpropanoic acid (2-PPA).

Table 9. Spectral parameters, Einstein probabilities $\left(A_{i f}\right.$ and $\left.B_{i f}\right)$, dipole strength $\left(D_{i f}\right)$, oscillator strength $\left(F_{i f}\right)$, lifetime $(\tau)$ and extinction coefficient $\left(\varepsilon_{\max }\right)$ of the electronic transition bands of 2-Phenylpropanoic acid (2-PPA) in different solvents.

\begin{tabular}{|c|c|c|c|c|c|c|c|}
\hline Solvent & $\lambda_{\max } \mathrm{nm}$ & $A_{i f} \times 10^{-7} \mathrm{~S}^{-1}$ & $B_{i f} \times 10^{-7} \mathrm{~S} \cdot \mathrm{g}^{-1}$ & $D_{i f} \times 10^{18}$ & $F_{f} \times 10^{2}$ & $\begin{array}{c}\varepsilon_{\max } \\
\left(\text { mole } \cdot \mathrm{L}^{-1} \cdot \mathrm{cm}^{-1} \text { ) }\right.\end{array}$ & $\tau \mathrm{ns}$ \\
\hline \multirow{2}{*}{ Ethanol } & 228.23 & 2.16 & 5.16 & 3.56 & 1.69 & 728.83 & 46.37 \\
\hline & 256.93 & 0.354 & 1.21 & 0.834 & 0.352 & 181.25 & 282.46 \\
\hline \multirow{2}{*}{ Methanol } & 227.71 & 1.70 & 4.03 & 2.78 & 1.32 & 675.83 & 58.97 \\
\hline & 256.93 & 0.316 & 1.08 & 0.744 & 0.31 .4 & 161.75 & 316.46 \\
\hline \multirow{2}{*}{ Isopropanol } & 228.55 & 1.71 & 4.11 & 2.84 & 1.35 & 728.01 & 58.39 \\
\hline & 256.98 & 0.316 & 1.08 & 0.442 & 0.314 & 167.77 & 316.46 \\
\hline \multirow{2}{*}{ Cyclohexane } & 229.40 & 1.42 & 3.46 & 2.38 & 1.13 & 682.04 & 70.24 \\
\hline & 256.76 & 0.354 & 1.21 & 0.832 & 0.352 & 183.75 & 282.46 \\
\hline \multirow{2}{*}{$\begin{array}{l}\text { Bidistilled } \\
\text { water }\end{array}$} & 227.71 & 1.95 & 4.63 & 3.19 & 1.52 & 708.69 & 51.24 \\
\hline & 257.24 & 0.363 & 1.24 & 0.856 & 0.361 & 201.10 & 275.48 \\
\hline \multirow{2}{*}{ Mineral water } & 227.19 & 1.93 & 4.56 & 3.15 & 1.50 & 714.14 & 51.69 \\
\hline & 257.11 & 0.373 & 1.27 & 0.879 & 0.0371 & 198.51 & 268.10 \\
\hline Chloroform & 258.23 & 0.397 & 1.37 & 94.7 & 0.0398 & 186.17 & 251.89 \\
\hline
\end{tabular}

Table 10. Singlet transition energies of 2-Phenylpropanoic acid in gaseous state.

\begin{tabular}{|c|c|c|c|c|c|c|}
\hline $\begin{array}{c}\text { Excited State } \\
\text { Singlet-A }\end{array}$ & Eigenvectors & Transition & $\Delta \mathrm{E} \mathrm{eV}$ & $\lambda_{\text {calc. }} \mathrm{nm}$ & $\mathrm{F}$ & $\lambda_{\text {exp. }} \mathrm{nm}$ \\
\hline \multicolumn{7}{|c|}{ Excited State 1} \\
\hline $38 \rightarrow 41$ & 0.38938 & $\psi_{m-2} \rightarrow \psi_{m+1}$ & \multirow{5}{*}{5.0799} & \multirow{5}{*}{244} & \multirow{5}{*}{0.0310} & \multirow{5}{*}{257} \\
\hline $38 \rightarrow 44$ & 0.15307 & $\psi_{m-2} \rightarrow \psi_{m+4}$ & & & & \\
\hline $40 \rightarrow 41$ & 0.49968 & $\psi_{m} \rightarrow \psi_{m+1}$ & & & & \\
\hline $40 \rightarrow 42$ & 0.12154 & $\psi_{m} \rightarrow \psi_{m+2}$ & & & & \\
\hline $40 \rightarrow 44$ & 0.13478 & $\psi_{m} \rightarrow \psi_{m+4}$ & & & & \\
\hline \multicolumn{7}{|c|}{ Excited State 2} \\
\hline $38 \rightarrow 41$ & 0.14958 & $\psi_{m-2} \rightarrow \psi_{m+1}$ & \multirow{7}{*}{5.3127} & \multirow{8}{*}{233} & \multirow{7}{*}{0.0010} & \multirow{7}{*}{228} \\
\hline $39 \rightarrow 41$ & 0.49872 & $\psi_{m-1} \rightarrow \psi_{m+1}$ & & & & \\
\hline $39 \rightarrow 42$ & -0.12444 & $\psi_{m-1} \rightarrow \psi_{m+2}$ & & & & \\
\hline $39 \rightarrow 44$ & -0.13935 & $\psi_{m-1} \rightarrow \psi_{m+4}$ & & & & \\
\hline $40 \rightarrow 42$ & -0.35902 & $\psi_{m} \rightarrow \psi_{m+2}$ & & & & \\
\hline $40 \rightarrow 43$ & -0.23889 & $\psi_{m} \rightarrow \psi_{m+3}$ & & & & \\
\hline $40 \rightarrow 44$ & 0.10196 & $\psi_{m} \rightarrow \psi_{m+4}$ & & & & \\
\hline \multicolumn{6}{|c|}{ Excited State 3} & \\
\hline $38 \rightarrow 41$ & 0.46682 & $\psi_{m-2} \rightarrow \psi_{m+1}$ & \multirow{4}{*}{5.6450} & \multirow{4}{*}{220} & \multirow{4}{*}{0.0391} & \\
\hline $38 \rightarrow 44$ & 0.15992 & $\psi_{m-2} \rightarrow \psi_{m+4}$ & & & & \\
\hline $39 \rightarrow 41$ & -0.15381 & $\psi_{m-1} \rightarrow \psi_{m+1}$ & & & & \\
\hline $40 \rightarrow 41$ & -0.41663 & $\psi_{m} \rightarrow \psi_{m+1}$ & & & & \\
\hline
\end{tabular}


Table 11. Spectral parameters, Einstein probabilities $\left(A_{i f}\right.$ and $\left.B_{i f}\right)$, dipole strength $\left(D_{i f}\right)$,oscillator strength $\left(F_{i f}\right)$, lifetime $(\tau)$ and extinction coefficient $\left(\varepsilon_{\max }\right)$ of the electronic transition bands of 3-Phenylpropanoic acid (3-PPA) in different solvents.

\begin{tabular}{cccccccc}
\hline Solvent & $\lambda_{\max } \mathrm{nm}$ & $A_{\text {if }} \times 10^{-5} \mathrm{~S}^{-1}$ & $B_{\text {if }} \times 10^{-6} \mathrm{~S} \cdot \mathrm{g}^{-1}$ & $D_{\text {if }} \times 10^{20}$ & $F \times 10^{4}$ & $\varepsilon_{\max }\left(\mathrm{mole} \cdot \mathrm{L}^{-1} \cdot \mathrm{cm}^{-1}\right)$ & $T \mathrm{~ns}$ \\
\hline \multirow{2}{*}{ Ethanol } & 215.66 & 10.7 & 2.17 & 14.9 & 4.52 & 45.18 & 930.65 \\
& 259.03 & 2.82 & 0.985 & 6.79 & 2.85 & 17.43 & 3549.21 \\
\multirow{2}{*}{ Methanol } & 215.66 & 13.5 & 2.72 & 18.8 & 9.45 & 43.92 & 740.85 \\
& 259.05 & 2.93 & 1.02 & 7.06 & 2.96 & 17.72 & 3414.77 \\
Isopropanol & 215.10 & 12.9 & 2.58 & 17.8 & 8.98 & 45.14 & 775.76 \\
\multirow{2}{*}{ Cyclohexane } & 258.90 & 2.67 & 0.933 & 6.44 & 2.70 & 15.87 & 3739.84 \\
Bidistilled water & 25.94 & 35.5 & 0.760 & 5.24 & 2.59 & 25.37 & 2814.22 \\
Mineral water & 258.25 & 2.23 & 0.781 & 5.39 & 2.26 & 13.92 & 4486.45 \\
Chloroform & 258.47 & 2.86 & 1.19 & 8.17 & 3.44 & 19.97 & 2922.26 \\
\hline
\end{tabular}

Table 11. The first excited state of the minimum energy structure of 3-PPA, Figure 6, includes the transitions $\psi_{m-2} \rightarrow \psi_{m+1}, \psi_{m-2^{-}} \rightarrow \psi_{m+2}$ and $\psi_{m-2} \rightarrow \psi_{m+4}$, Table 12. The major transition in the first excited state is coming mainly from the transition $\psi_{m-2} \rightarrow \psi_{m+1}$, with eigenvector 0.65683 . The calculated transition energy between the ground state to the second excited state lies at $234 \mathrm{~nm}$ which is not far from the experimental band position 215 $\mathrm{nm}$ in the spectra of 3-PPA, Figure 7. The major transition in the second and third excited states include mainly the transition from $\psi_{m}$ to $\psi_{m+1}$ with eigenvectors 0.50780 and 0.46741 respectively. From comparison point of view of the spectral parameters, Table 8, Table 9, Table 11 between IBF and propanioc acid derivatives (2-PPA and 3-PPA), it can be noticed that the spectral parameters of IBF and 2-PPA namely Einstein transition probabilities $\left(A_{i f}\right.$ and $\left.B_{i f}\right)$ are close to each other but the dipole strengths $D_{i f}$, oscillator strengths, $f_{\text {if }}$ and extinction coefficients $\varepsilon_{\max }$, of IBF are higher than those of 2-PPA but the life times of excitation $\tau$, of 2-PPA are higher than those of IBF. From comparison general point of view, the spectral parameters of IBF and 2-PPA are higher than those of 3-PPA except the excitation life times of 3-PPA which are much higher than those of IBF and 2-PPA.

The blue or green colors (aquamarine) of the copper complexes as in the $\mathrm{Cu}(\mathrm{ligand})_{2}$ complex are due to the of absorption band in the region $600-900 \mathrm{~nm}$ in the spectra. For $\mathrm{Cu}(\mathrm{IBF})_{2}$ complex spectra, Figure 8, it has an absorption band at about $\lambda_{\max }=700 \mathrm{~nm}$ which is attributed to $\mathrm{d} \rightarrow \mathrm{d}$ transition [15]. From Table 13, the $\mathrm{d} \rightarrow \mathrm{d}$ transition band of copper ion has high life time of excitation more than 2000 ns which is much higher than the excitation time of the band at about $\lambda_{\max }=280 \mathrm{~nm}$, Figure 8. The Einstein transition probabilities $\left(A_{i f}\right.$ and $\left.B_{i f}\right)$, dipole strength $D_{i f}$, molar absorptivities $\varepsilon$ and oscillator strength $F_{i f}$ have much higher values at the absorption band at about $\lambda_{\max }=280 \mathrm{~nm}$ more than those at about $\lambda_{\max }=700 \mathrm{~nm}$. From Figure 3, Figure 8, it has been noticed that the first excitation band of IBF at $\lambda_{\max }=263$, has been red shifted to $\lambda_{\max }=280 \mathrm{~nm}$ in the spectra $\mathrm{Cu}(\mathrm{IBF})_{2}$ complex due to some planarity in the complex molecule, Figure 9.

From Table 14 of the spectral data of Zn-complex it can be concluded that this molecule has an absorption absorbance at the same wavelengths of IBF i.e. at $\lambda_{\max }=230$ and $\lambda_{\max }=263 \mathrm{~nm}$ as well as in the molar absorptivities of IBF, $\varepsilon_{\max }$, are not far from those of Zn-complex spectral data. There is satisfied resemblance between the values of the dipole strengths, $D_{\text {if }}$ and life time of excitation, $\tau$ in the spectral data of IBF and the complex Table 8 and Table 14, except the oscillator strengths of IBF spectral data, Table 8, are higher than those of the Zn-complex spectral data.

From the minimum energy structure of Zn-complex, Figure 10, shows that the IBF moieties in the complex are perpendicular to each other therefore the absorbance of the complex is confined in the absorption bands of IBF molecule at 228 and 263 nm, Figure 11 as in the case in the spectra of IBF, Figure 3. This appears clearly from their appreciable resemblance between their spectral data, Table 8 , Table 14 . This coincidence between the spectra of IBF and Zn-complex is coming out from the perpendicularity of the two IBF moieties in the complex therefore the conjugation overall the molecule is interrupted between the two IBF moieties in the complex. 


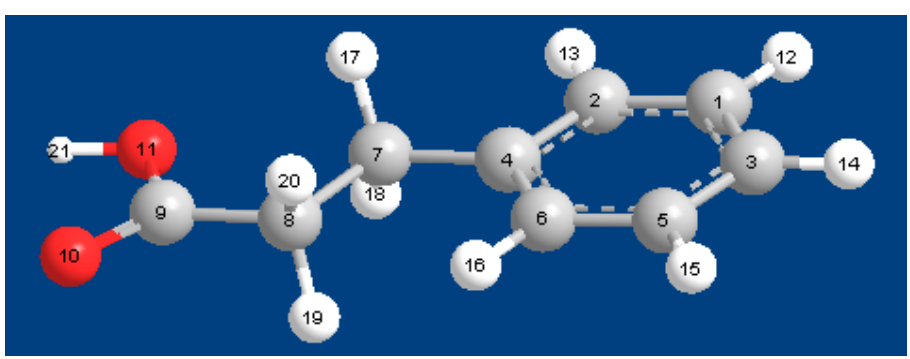

Figure 6. Minimum energy structure of 3-Phenylpropanoic acid (3-PPA).

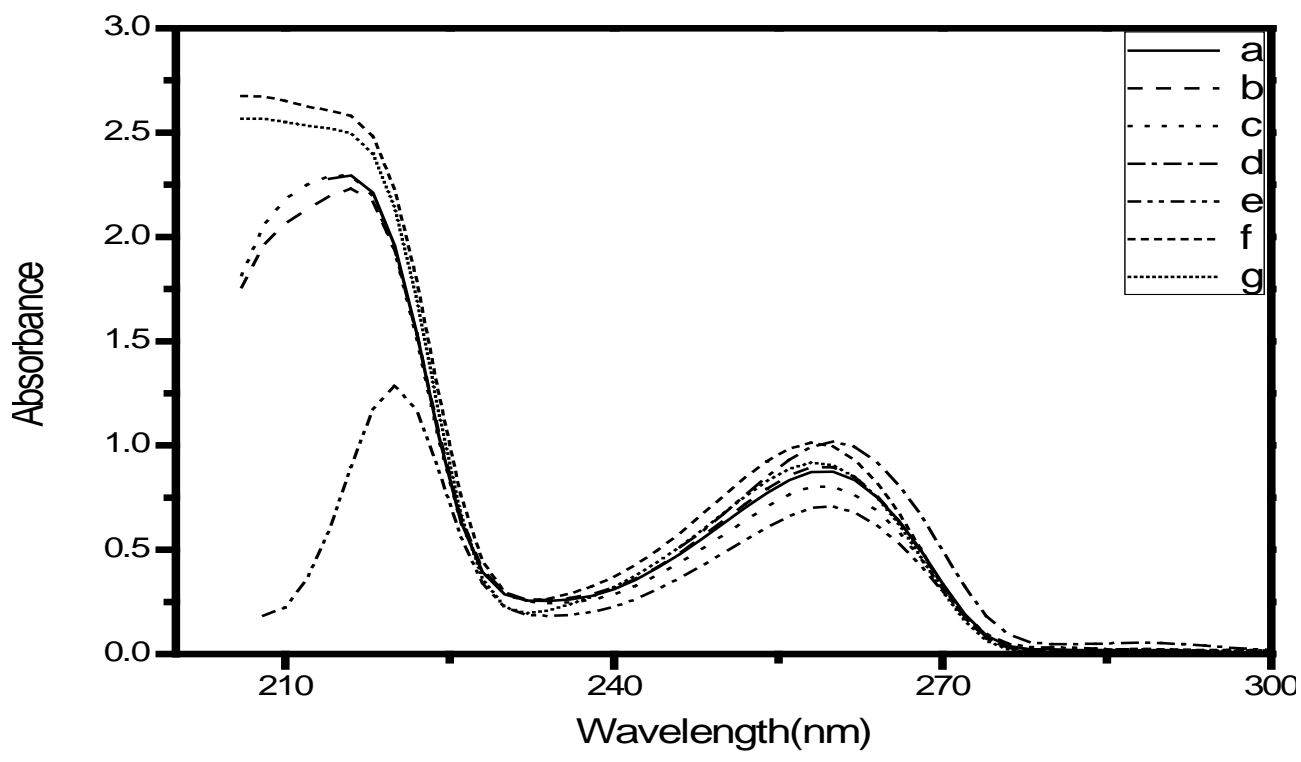

Figure 7. Electronic spectra of 3-Phenylpropanoic acid (50.7 $\mathrm{mmol} \cdot \mathrm{L}^{-1}$ ) in (a) EtOH, (b) $\mathrm{MeOH}$, (c) Isopropanol, (d) $\mathrm{CHCl}_{3}$, (e) Cyclohexane, (f) Bidistilled water, and (g) Mineral water.

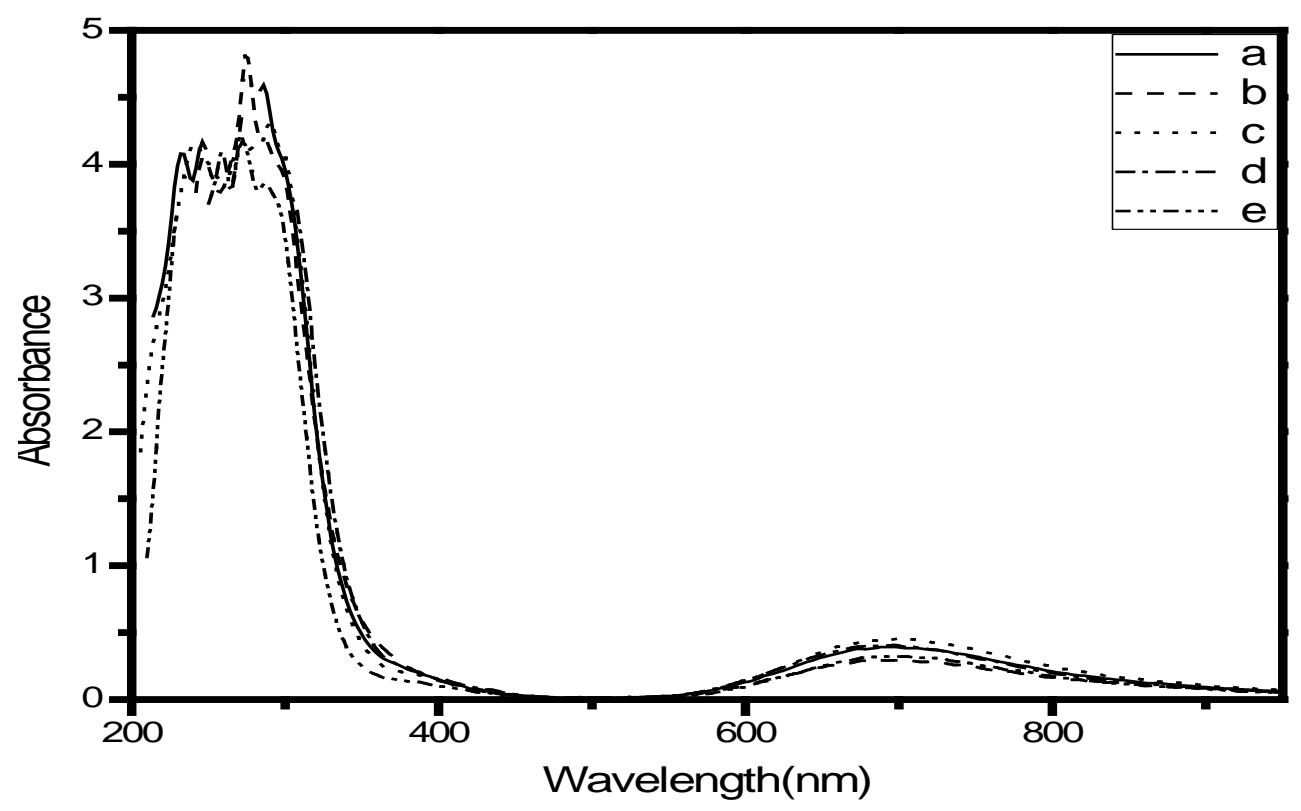

Figure 8. Electronic spectra of Cu-Ibuprofen complex $\left(1.9 \mathrm{mmol} \cdot \mathrm{L}^{-1}\right)$ in (a) $\mathrm{EtOH}$, (b) $\mathrm{MeOH}$, (c) Isopropanol, (d) $\mathrm{CHCl}_{3}$, and (e) Cyclohexane. 


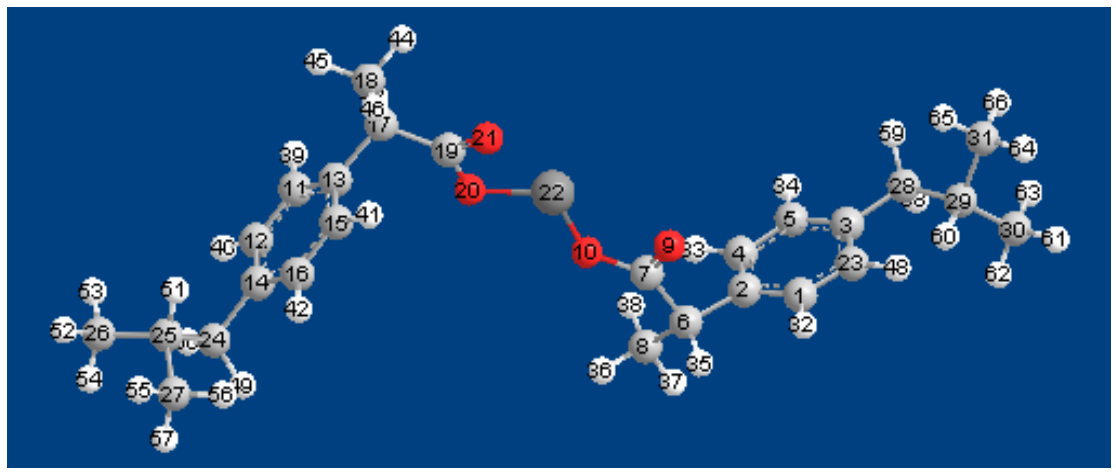

Figure 9. Minimum energy structure of $\mathrm{Cu}(\mathrm{IBF})_{2}$ complex.

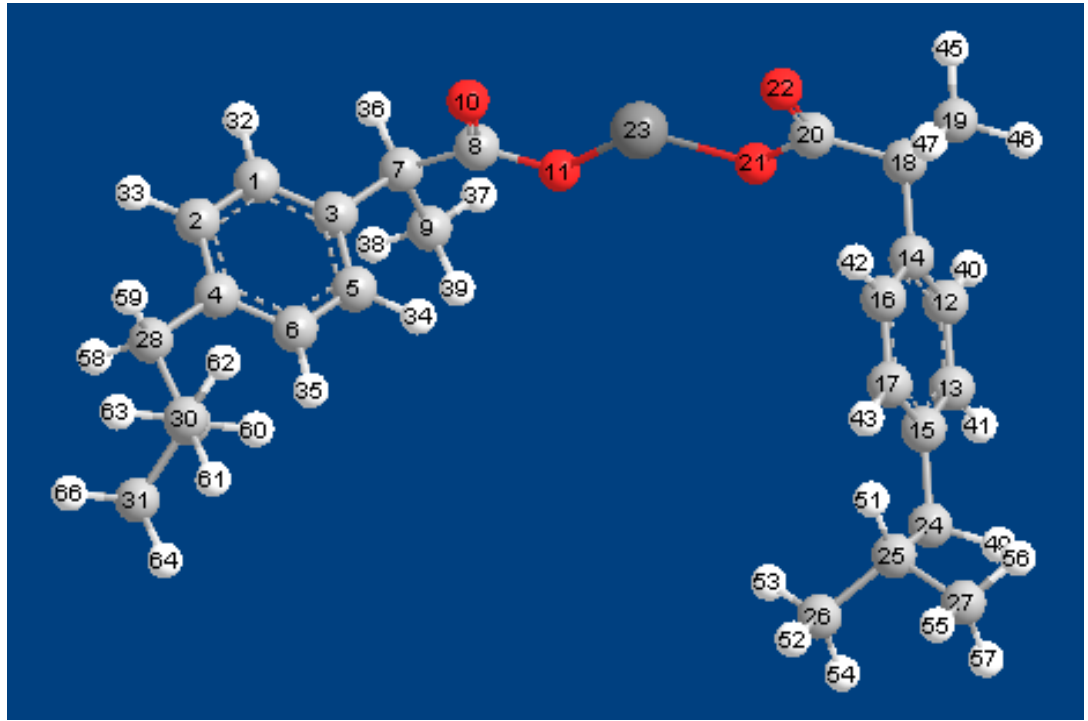

Figure 10. Minimum energy structure of $\mathrm{Zn}(\mathrm{IBF})_{2}$ complex, [11].

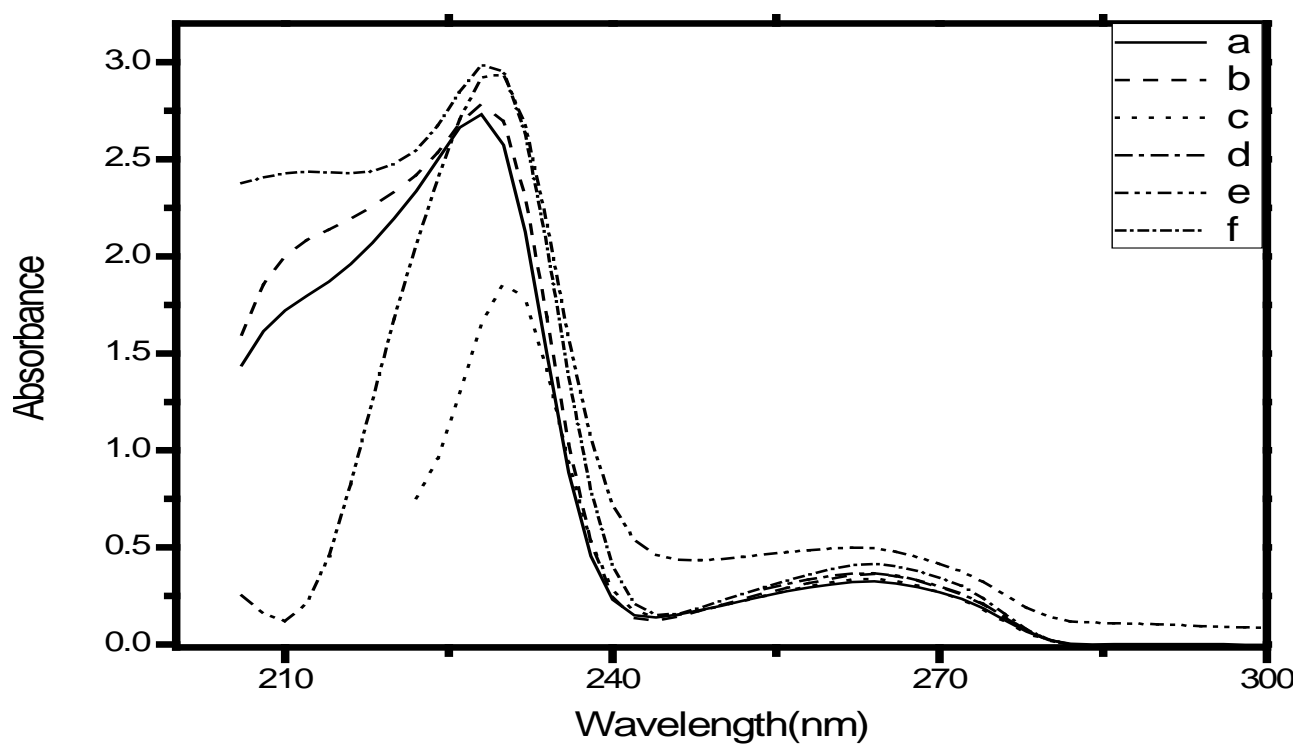

Figure 11. Electronic spectra of $\mathrm{Zn}(\mathrm{IBF}) 2 .-2 \mathrm{H}_{2} \mathrm{O}$ complex $\left(1.17 \mathrm{mmol} \cdot \mathrm{L}^{-1}\right)$ in (a) $\mathrm{EtOH}$, (b) $\mathrm{MeOH}$, (c) Isopropanol, (d) $\mathrm{CHCl}_{3}$, (e) Cyclohexane, and (f) Bidistilled water. 
Table 12. Singlet transition energies of 3-Phenylpropanoic acid.

\begin{tabular}{|c|c|c|c|c|c|c|}
\hline $\begin{array}{l}\text { Excited State } \\
\text { Singlet-A }\end{array}$ & Eigenvectors & Transition & $\Delta \mathrm{E} \mathrm{eV}$ & $\lambda_{\text {calc. }} \mathrm{nm}$ & $\mathrm{F}$ & $\lambda_{\text {exp. }} \mathrm{nm}$ \\
\hline \multicolumn{7}{|c|}{ Excited State 1} \\
\hline $\begin{array}{l}38 \rightarrow 41 \\
38 \rightarrow 42 \\
38 \rightarrow 44\end{array}$ & $\begin{array}{c}0.65683 \\
-0.16373 \\
-0.10939\end{array}$ & $\begin{array}{l}\psi_{m-2} \rightarrow \psi_{m+1} \\
\psi_{m-2} \rightarrow \psi_{m+2} \\
\psi_{m-2} \rightarrow \psi_{m+4}\end{array}$ & 5.2628 & 236 & 0.0001 & 259 \\
\hline \multicolumn{7}{|c|}{ Excited State 2} \\
\hline $\begin{array}{l}39 \rightarrow 41 \\
39 \rightarrow 42 \\
39 \rightarrow 44 \\
40 \rightarrow 41 \\
40 \rightarrow 44\end{array}$ & $\begin{array}{c}-0.15524 \\
-0.31449 \\
0.16121 \\
0.50780 \\
0.30508\end{array}$ & $\begin{aligned} \psi_{m-1} & \rightarrow \psi_{m+1} \\
\psi_{m-1} & \rightarrow \psi_{m+2} \\
\psi_{m-1} & \rightarrow \psi_{m+4} \\
\psi_{m} & \rightarrow \psi_{m+1} \\
\psi_{m} & \rightarrow \psi_{m+4}\end{aligned}$ & 5.3097 & 234 & 0.0107 & 215 \\
\hline \multicolumn{7}{|c|}{ Excited State 3} \\
\hline $\begin{array}{l}39 \rightarrow 41 \\
39 \rightarrow 42 \\
40 \rightarrow 41 \\
40 \rightarrow 42 \\
40 \rightarrow 44\end{array}$ & $\begin{array}{c}0.13112 \\
0.24926 \\
0.46741 \\
-0.24198 \\
-0.37012 \\
\end{array}$ & $\begin{aligned} \psi_{m-1} & \rightarrow \psi_{m+1} \\
\psi_{m-1} & \rightarrow \psi_{m+2} \\
\psi_{m} & \rightarrow \psi_{m+1} \\
\psi_{m} & \rightarrow \psi_{m+2} \\
\psi_{m} & \rightarrow \psi_{m+4}\end{aligned}$ & 5.5265 & 224 & 0.0044 & \\
\hline
\end{tabular}

Table 13. Spectral parameters, Einstein probabilities $\left(A_{i f}\right.$ and $\left.B_{i f}\right)$, dipole strength $\left(D_{i f}\right)$, oscillator strength $\left(F_{i f}\right)$, lifetime $(\tau)$ and extinction coefficient $\left(\varepsilon_{\max }\right)$ of the electronic transition bands of $\mathrm{Cu}^{+2}$ ion in $\mathrm{Cu}(\mathrm{IBF})_{2}$ complex in different solvents.

\begin{tabular}{cccccccc}
\hline Solvent & $\lambda_{\max } \mathrm{nm}$ & $A_{\text {if }} \times 10^{-6} \mathrm{~S}^{-1}$ & $B_{\text {if }} \times 10^{-8} \mathrm{~S} \cdot \mathrm{g}^{-1}$ & $D_{\text {if }} \times 10^{18}$ & $f_{\text {if }} \times 10^{3}$ & $\varepsilon_{\max }\left(\mathrm{mole} \cdot \mathrm{L}^{-1} \cdot \mathrm{cm}^{-1}\right)$ & $\tau \mathrm{ns}$ \\
\hline \multirow{2}{*}{ Ethanol } & 285.98 & 157 & 7.37 & 50.8 & 193 & 2414.24 & 6.37 \\
& 694.42 & 0.486 & 0.328 & 2.26 & 3.53 & 206.27 & 2057.61 \\
\multirow{2}{*}{ Methanol } & 275.02 & 107 & 4.48 & 30.9 & 122 & 2527.24 & 9.35 \\
& 693.64 & 0.384 & 0.258 & 1.78 & 2.78 & 154.24 & 2604.17 \\
Isopropanol & 291.04 & 142 & 7.04 & 48.6 & 181 & 2265.86 & 7.04 \\
& 699.87 & 0.556 & 0.383 & 2.64 & 4.10 & 238.56 & 1798.56 \\
Chloroform & 275.58 & 88.7 & 3.73 & 25.8 & 101 & 2305.71 & 11.27 \\
& 695.78 & 0.515 & 0.349 & 2.41 & 3.76 & 214.75 & 1941.75 \\
Cyclohexane & 272.74 & 127 & 5.19 & 35.8 & 143 & 2187.01 & 7.87 \\
& 703.37 & 0.376 & 0.263 & 1.81 & 2.80 & 169.81 & 2659.57 \\
\hline
\end{tabular}

Table 14. Spectral parameters, Einstein probabilities $\left(A_{i f}\right.$ and $\left.B_{i f}\right)$, Dipole strength $\left(D_{i f}\right)$, Oscillator strength $\left(F_{i f}\right)$, Lifetime $(\tau)$ and Extinction coefficient $\left(\varepsilon_{\max }\right)$ of the electronic transition bands of $\mathrm{Zn}(\mathrm{IBF})_{2} \cdot 2 \mathrm{H}_{2} \mathrm{O}$ in different solvents.

\begin{tabular}{cccccccc} 
Solvent & $\lambda_{\max } \mathrm{nm}$ & $A_{\text {if }} \times 10^{-7} \mathrm{~S}^{-1}$ & $B_{\text {if }} \times 10^{-7} \mathrm{~S} \cdot \mathrm{g}^{-1}$ & $D_{\text {if }} \times 10^{18}$ & $F_{f} \times 10^{3}$ & $\varepsilon_{\max }\left(\mathrm{mole} \cdot \mathrm{L}^{-1} \cdot \mathrm{cm}^{-1}\right)$ & $\tau \mathrm{ns}$ \\
\hline \multirow{2}{*}{ Ethanol } & 227.67 & 2.17 & 5.16 & 3.56 & 0.170 & 2325.29 & 46.08 \\
& 263.60 & 0.528 & 1.95 & 1.34 & 5.53 & 281.74 & 189.39 \\
\multirow{2}{*}{ Methanol } & 227.99 & 2.95 & 7.03 & 4.85 & 0.231 & 2372.86 & 33.90 \\
& 263.90 & 0.542 & 2.00 & 1.38 & 5.68 & 313.70 & 184.50 \\
Isopropanol & 230.07 & 2.17 & 5.32 & 3.67 & 0.173 & 1592.12 & 46.08 \\
Chloroform & 263.21 & 0.509 & 1.87 & 1.29 & 5.31 & 288.61 & 196.46 \\
\multirow{2}{*}{ Cyclohexane } & 262.82 & 0.522 & 1.91 & 1.32 & 5.43 & 311.87 & 191.57 \\
& 228.94 & 4.95 & 11.9 & 8.23 & 0.390 & 2505.71 & 20.20 \\
Bidistilled water & 262.95 & 0.911 & 3.33 & 2.30 & 9.49 & 421.21 & 109.77 \\
& 26.29 & 5.44 & 13.2 & 9.08 & 0.430 & 2547.47 & 18.38 \\
\hline
\end{tabular}




\subsection{Anticancer Effect of Ibuprofen Drug}

To deepen the denotation of cancer, it is mutual electron transfer between the nucleic acid bases and electron donor or electron acceptor, i.e. free radicals, drugs even some food like grills and fries. Losing an electron from the nucleic acid bases inside the nucleus produces carcinogenic cell in which the nucleus acts as electron donor to any electron acceptor such as in case of Paracetamol metabolite in the liver, NABQI, Figure 12 having high electron affinity being sufficient to withdraw an electron from guanine in the nucleus of liver cell in absence of glutathione [12]. Therefore the nucleus looses an electron producing cationic nucleus as a free radical which can behave as positive carcinogenic cell. The positive cancer means that the nucleus lacks an electron due to the mutual electron transfer; therefore it behaves abnormally i.e. cancer. This type of cancer can be treated by drugs having spontaneous electron donor character in a certain condition to compensate the electron deficiency from the nucleus such as Ibuprofen drug in its anionic forms.

After administration of Ibuprofen drug, it passes via human stomach of $\mathrm{pH} \sim 2$ and in full stomach of $\mathrm{pH} \sim 4$ 5 saving the molecular form of the drug AH. After the drug arrival to gastrointestine of $\mathrm{pH} \sim 8-9$, therefore the anionic form $\mathrm{A}^{-}$of Ibuprofen drug exists side by side with the molecular form $\mathrm{AH}$ in intestine. The ionization constant of Ibuprofen dsrug $\mathrm{pK}_{\mathrm{a}}=\mathrm{s} 4.85$, using the relation:

$$
\mathrm{pH}=\mathrm{pK}_{\mathrm{a}}+\log \left(\mathrm{A}^{-} / \mathrm{AH}\right)
$$

Therefore the ratio between anions $\mathrm{A}^{-}$and molecules $\mathrm{AH}$ being equal to 1 approximately. The $\mathrm{pH}$ value of human blood equals to 7.4 and its $\mathrm{pK}_{\mathrm{a}}=5.2$, hence the ratio between anions $\mathrm{A}^{-}$and molecules $\mathrm{AH}$ is still nearly equal to 1 . Therefore Ibuprofen drug exists in the intestine and in the blood as the anionic form $\mathrm{A}^{-}$and the molecular form AH. The existence of free molecule of the drug $\mathrm{AH}$ together with the anion $\mathrm{A}^{-}$in the intestine establishes equilibrium between them. This mixture is spontaneous electron donor to the carcinogenic cells rendering them being in normal state.

$$
\mathrm{AH} \leftrightarrow \mathrm{A}^{-}+\mathrm{H}^{+}
$$

The ionization energy, Ip, of Ibuprofen drug molecule by DFT method in the stomach being equal to, 6.6804 $\mathrm{eV}$, and decreases when the drug arrives to the small intestine at which the $\mathrm{pH}$ value lies between $8-9$ and the value of the ionization potential decreases to $0.9015 \mathrm{eV}$, table. Therefore the Ibuprofen drug behaves as spontaneous electron donor in the small intestine. In the same way, the electron affinity of Ibuprofen drug molecule in the stomach is equal to $0.81634 \mathrm{eV}$, table, which decreases in the small intestine to be $-1.4392 \mathrm{eV}$. This means that Ibuprofen drug anion hasn't the ability to receive an electron from the IBF molecules. Spontaneous electron donor to nucleic acid bases must fulfill the following condition:

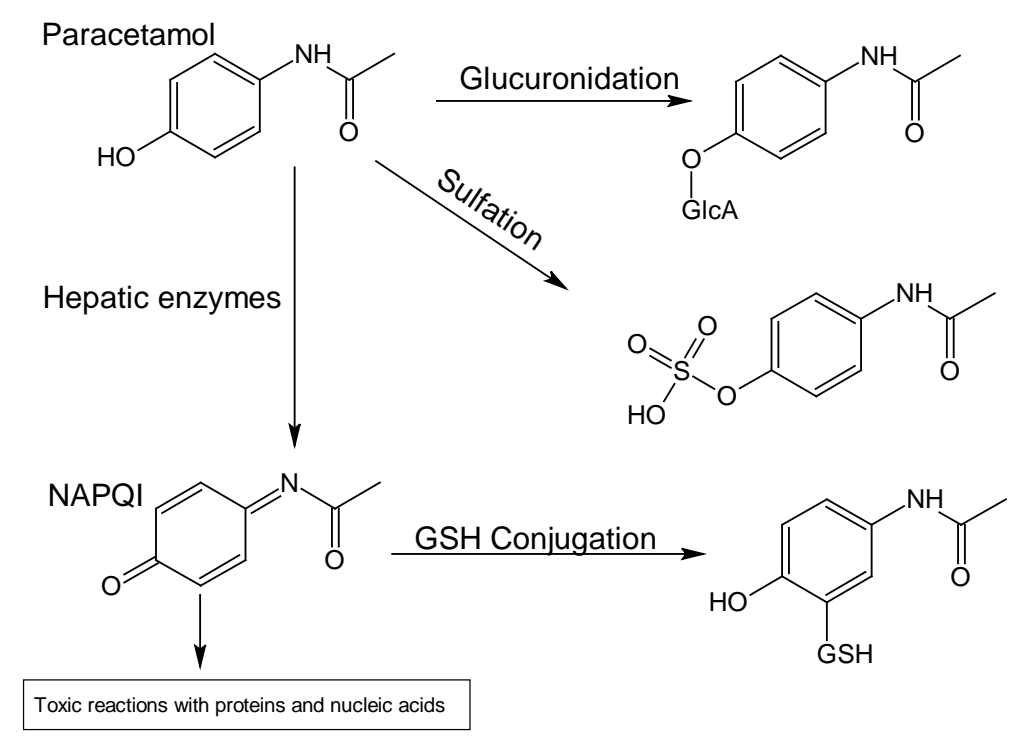

Figure 12. Three path ways of Paracetamol metabolism. 


$$
[\mathrm{Ip}(\text { anion })-\mathrm{Ea}(\mathrm{NAB})] \leq 0
$$

where Ip is the ionization potential energy of the anion and $\mathrm{Ea}(\mathrm{NAB})$ is the electron affinity of nucleic acid bases.

From comparison point of view with respect to the nucleic acid bases it has been found the following values of the electronic total energy, ionization energy and electron affinity in the following Table 16.

From Table 15, it has been found that guanine has the lowest Ip, 6.1879 among all the other nucleic acid bases hence it acts as an electron donor forming the cationic nucleus of the carcinogenic cell.

Since Ibuprofen in the small intestine has very low ionization energy, $0.9015 \mathrm{eV}$ and the electron affinity values of nucleic acid bases are higher than that of IBF anion; therefore IBF anions in the presence of IBF molecules can act as spontaneous electron donor to compensate the electron deficiency of the carcinogenic cells in the intestine. The presence of the mixture of $\mathrm{A}^{-}$and $\mathrm{AH}$ in the blood gives the chance to inhibit different types of cancers such as protostate, lung and breast cancers [2]-[4].

From the previous Table 16, it can be concluded that the anions of (2PPA) and (3-PPA) have Ip values which are lower than that of the anion of IBF therefore these two compounds can act as spontaneous electron donor and can be used as stronger anticancer more than IBF drug. The heat contents $(\Delta \mathrm{H})$ of alteration of AH molecule to its $\mathrm{A}^{-}$anion for the studied compounds (IBF, 2-PPA and 3-PPA) have the following values respectively, $352.393,347.619$ and $349.504 \mathrm{k} \cdot \mathrm{scal} \cdot \mathrm{mol}^{-1}$ at $37^{\circ} \mathrm{C}$. Therefore this mixture of molecules and anions of the studied compounds are anticancer [2]-[4].

\subsection{Metabolism of IBF Drug}

The metabolic activation may be via chiral inversion not only leads to higher therapeutic potency; from another hand it may also cause a great risk of acute kidney failure in patients with renal disorder. The side effect of Ibuprofen includes gastrointestinal disturbance and central nervous system (CNS) depression. All of these adverse effects are found to be mild, [16]. After arrival of ibuprofen to the blood after absorption from the small intestine to follow up via blood of $\mathrm{pH} 7.4$ toward liver where its metabolism takes place to give ibuprofen acylglucuronide, [16] [17], oxidation to produce two major metabolites, 2-hydroxyibuprofen (2HIBF) and carboxy-ibuprofen (CIBF), Figure 13. The other minor oxidation products are: 1-hydroxyibuprofen (1HIBF), 3-hydroxyibuprofen (3HIBF) and 2-(4-carboxyphenyl) propanoic acid (CPPA) were detected in the human urine. CYP2C9 is the predominant enzyme which is responsible for the oxidation metabolism of Ibuprofen (IBF). The DFT Parameters including total electronic energy (TE), ionization potential (Ip) and electron affinity (Ea) of the metabolite products are given in the following Table 17.

Table 15. DFT/6-31G**Parameters of nucleic acid bases (N.A.B.) and IBF drug.

\begin{tabular}{cccc}
\hline Compound & TE au & Ip eV & Ea eV \\
\hline Adenine & -467.17488 & 6.4061 & +1.2672 \\
Guanine & -542.37704 & 6.1879 & +1.2828 \\
Cytosine & -394.82291 & 6.5819 & +1.4768 \\
Uracil & -414.70313 & 7.3316 & +1.8626 \\
S-Ibuprofen in the Stomach & -656.5408 & 6.6837 & +0.8879 \\
S-Ibuprofen in the small intestine & -655.9788 & 0.9015 & -1.4392 \\
\hline
\end{tabular}

TE is the total energy, Ip is the ionization energy, Ea is the electron affinity.

Table 16. Anions DFT-parameters of IBF Drug and some analogues.

\begin{tabular}{cccc}
\hline Anion & TE au & Ip eV & Ea eV \\
\hline IBF & -655.9788 & 0.9015 & -1.4392 \\
2-PPA & -498.7676 & 0.8966 & -2.0580 \\
3-PPA & -498.7635 & 0.6289 & -1.7385 \\
\hline
\end{tabular}




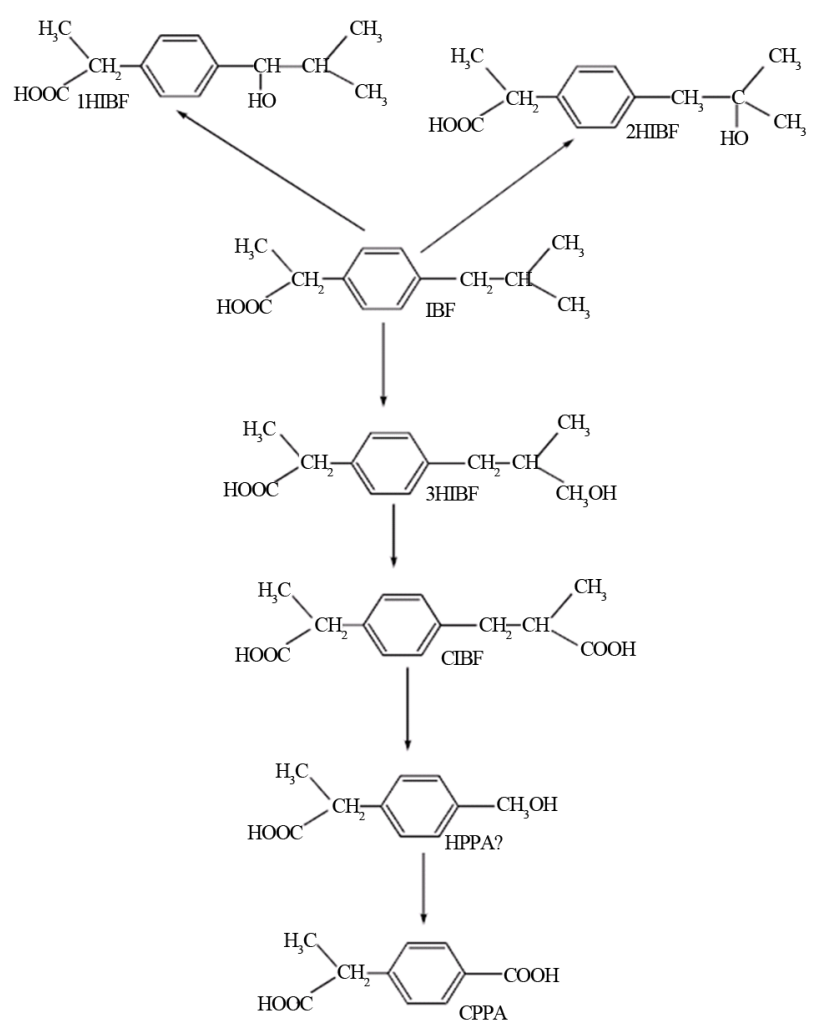

Figure 13. Metabolic pathways for ibuprofen, [16] [17]—HPPA has not been detected.

Table 17. Anions DFT-parameters of IBF drug and some analogues.

\begin{tabular}{cccc}
\hline Compound & TE & Ip & Ea \\
\hline S-IBF & -656.54088 & 6.6804 & 0.8163 \\
1HIBF & -731.73070 & 6.8831 & 1.0591 \\
2HIBF & -731.73523 & 6.5980 & 0.8376 \\
3HIBF & -731.72320 & 6.8916 & 1.0803 \\
CIBF & -805.74479 & 6.8097 & 1.0071 \\
CPPA & -687.83361 & 7.5253 & 2.0444 \\
\hline
\end{tabular}

From comparative point of view, the Ip's and Ea's of the metabolite products of IBF, Table 17, Figure 14, with those of nucleic acid bases, Table 15 using the same method of calculations, it can be concluded that all the values of Ip's and Ea's of the IBF metabolite products are consistent with those of the nucleic acid bases. Therefore there isn't possibility of electron transfer between them and the acidic metabolites tend to have some anionic forms in the slightly basic medium in the human blood, 7.4, hence, the metabolite products of IBF are safe from cancer effect in the liver or in the kidney.

From the different values of Ip's of nucleic acid bases, Table 15, it has been found that guanine has the lowest Ip value among all the other nucleic acid bases, $6.1879 \mathrm{eV}$ and with respect to that of 1 HIBF metabolite, $6.8831 \mathrm{eV}$. The metabolite $1 \mathrm{HIBF}$ has an electron affinity being equal to $1.0591 \mathrm{eV}$. Therefore guanine acts as electron donor with respect to 1 HIBF metabolite and the electron transfer energy between them reaches to 3.841 $\mathrm{eV}$ which is corresponding to a wavelength being equal to $322 \mathrm{~nm}$. The electron affinity of uracil, $1.8626 \mathrm{eV}$, Table 15, is higher than that of 2HIBF, $0.8376 \mathrm{eV}$, and the ionization energy of uracil, $7.3316 \mathrm{eV}$ is higher than that of 2HIBF, $6.598 \mathrm{eV}$ therefore uracil acts as electron acceptor with respect to 2HIBF metabolite to produce the negative cancer of the anionic nucleus. Therefore the electron transfer energy barrier, $4.734 \mathrm{eV}$ (262 nm) 


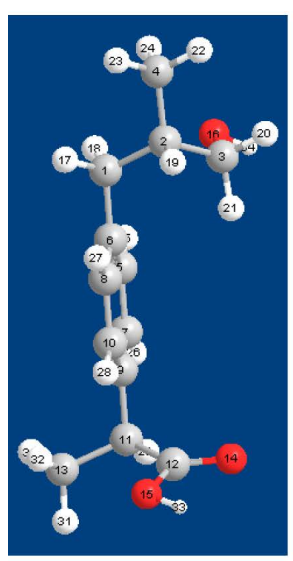

$1 \mathrm{HIBF}$

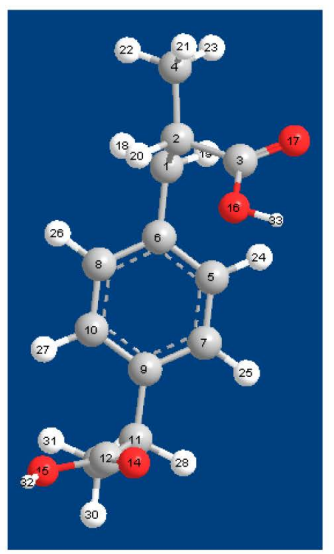

CIBF

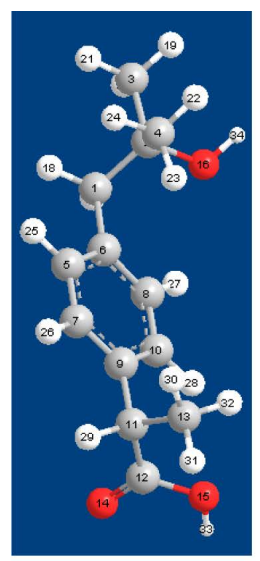

$2 \mathrm{HIBF}$

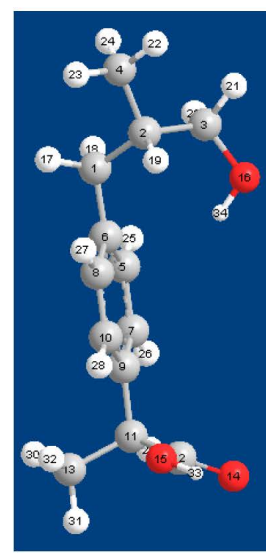

$3 \mathrm{HIBF}$

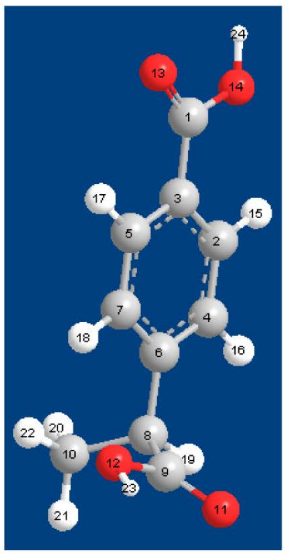

CPPA

Figure 14. The minimum energy structures of IBF metabolites in the human body.

prevents the electron transfer between them [12] [18] [19] leading to the absence of the cancer disease in the liver. From general point of view, guanine due to its lowest Ip and low Ea, acts as electron donor producing positive cancer and uracil due to its high Ea and high Ip, acts as an electron acceptor producing negative cancer. Generally, the anion of 3-PPA is more electron donor than that of IBF in Table 16, since 3-PPA anion has the lowest ionization energy. Therefore it is advisable to use this compound instead of IBF as a drug to inhibit positive cancer diseases.

\section{Conclusions}

1) It is good for the health to take Ibuprofen drug regularly to avoid cancers of gastrointestine, protostate, breast and lung.

2) 2PPA and 3-PPA are better as anticancer than Ibuprofen drug.

3) Ibuprofen metal ion complexes are not anti-cancers like anions of IBF, 2-PPA and 3-PPa.

\section{References}

[1] Torre, L.A., Bray, F., Siegel, R.L., Ferlay, J., Lortet-Tieulent, J. and Jemal, A. (2015) Global Cancer Statistics 2012. CA: A Cancer Journal for Clinicians, 65, 87-108. http://dx.doi.org/10.3322/caac.21262

[2] Akrami, H., Aminzadeh, S. and Fallahi, H. (2015) Inhibitory Effect of Ibuprofen on Tumor Survival and Angiogenesis in Gastric Cancer Cell. Tumor Biology, 36, 3237-3243. http://dx.doi.org/10.1007/s13277-014-2952-3

[3] Harris, R.E., Beebe-Donk, J., Doss, H. and Doss, D.B. (2005) Aspirin, Ibuprofen, and Other Non-Steroidal Anti-In- 
flammatory Drugs in Cancer Prevention: A Critical Review of Non-Selective COX-2 Blockade (Review). 13, 559583. http://dx.doi.org/10.3892/or.13.4.559

[4] Harris, R.E., Beebe-Donk, J. and Alshafie, G.A. (2007) Reduced Risk of Human Lung Cancer by Selective Cyclooxygenase 2 (Cox-2) Blockade: Results of a Case Control Study. International Journal of Biological Sciences, 3, 328334. http://dx.doi.org/10.7150/ijbs.3.328

[5] Hanlon, G., Kooloobandi, A. and Hutt, A. (1994) Microbial metabolism of 2-Arylpropanoic Acids: Effect of Environment on the Metabolism of Ibuprofen by Verticillium lecanii. Journal of Applied Bacteriology, 76, 442-447. http://dx.doi.org/10.1111/j.1365-2672.1994.tb01100.x

[6] Li, T. and Feng, S. (2006) Empirically Augmented Density Functional Theory for Predicting Lattice Energies of Aspirin, Acetaminophen Polymorphs, and Ibuprofen Homochiral and Racemic Crystals. Pharmaceutical Research, 23, 2326-2332. http://dx.doi.org/10.1007/s11095-006-9006-5

[7] Vueba, M., Pina, M. and de Carvalho, L.B. (2008) Conformational Stability of Ibuprofen: Assessed by DFT Calculations and Optical Vibrational Spectroscopy. Journal of Pharmaceutical Sciences, 97, 845-859. http://dx.doi.org/10.1002/jps.21007

[8] Okulik, N. and Jubert, A.H. (2006) Theoretical Study on the Structure and Reactive Sites of Three Non-Steroidal Anti-Inflammatory Drugs: Ibuprofen, Naproxen and Tolmetin Acids. Journal of Molecular Structure: THEOCHEM, 769, 135-141. http://dx.doi.org/10.1016/j.theochem.2005.10.061

[9] Liu, L. and Gao, H. (2012) Molecular Structure and Vibrational Spectra of Ibuprofen Using Density Function Theory Calculations. Spectrochimica Acta Part A: Molecular and Biomolecular Spectroscopy, 89, 201-209. http://dx.doi.org/10.1016/j.saa.2011.12.068

[10] Frazier, D., Lynch, S. and Carlisle, G. (1981) Synthesis and Magnetic Properties of Bis [2-(4-Isobutylphenyl) Propionato] Copper (II). Journal of Inorganic and Nuclear Chemistry, 43, 2747-2748. http://dx.doi.org/10.1016/0022-1902(81)80610-0

[11] Tita, B., Stefanescu, M. and Tita, D. (2011) Complexes of Anti-Inflammatory Non-Steroidal Drugs from Carboxylic Acids Family 1. Synthesis and Characterization of Zn (II) Complex with Ibuprofen. Revista de Chimie, 62, 1060-1064.

[12] El-Shahawy, A. (2014) DFT Cancer Energy Barrier and Spectral Studies of Aspirin, Paracetamol and Some Analogues. Computational Chemistry, 2, 6-17. http://dx.doi.org/10.4236/cc.2014.21002

[13] El-Shahawy, A. (2011) Computational DFT/CI Spectroscopic Structural Studies of Some Complexes of Benzalbarbituric Acid. Journal of Molecular Structure, 987, 232-240. http://dx.doi.org/10.1016/j.molstruc.2010.12.030

[14] El-Shahawy, A.S., Girgis, M.M. and Ismail, M.T. (1987) Nicotinic Acid and Nicotinamide Electronic Structural Studies. Spectrochimica Acta, 43A, 1371-1375. http://dx.doi.org/10.1016/S0584-8539(87)80013-2

[15] Cotton, F.A. and Wilkinson, G. (1972) Advanced Inorganic Chemistry. 3rd Edition, John Wiey \& Sons, Inc., New York.

[16] Huq, F. (2006) Molecular Modeling Analysis of the Metabolism of Ibuprofen. Journal of Pharmacology and Toxicology, 1, 456-463.

[17] Tan, S.C., Patel, B.K., Jackson, S.H.D., Swift, C.G. and Hutt, A.J. (2002) Stereo-Selectivity of Ibuprofen Metabolism and Pharmacokinetics Following the Administration of the Racemate to Healthy Volunteers. British Journal of Anaesthesia, 32, 683-697.

[18] El-Shahawy, A. and Hammam, A.S. (2004) CNDO/SCF Molecular Orbital Structural Studies And Charge Transfer Complex Formation between 4,4'Dimethoxydiquinine and Uracil. Bull. Bulletin of the Chemical Society of Ethiopia, 18, 193-204. http://dx.doi.org/10.4314/bcse.v18i2.61444

[19] El-Shahawy, A. (1991) Electronic Spectroscopic Studies on L-Ascorbic Acid and Adenine. Acta Chimica Hungarica, 128, 737-750. 